\title{
Un museo virtual universitario para la recuperación de Memoria Histórica
}

\section{A university virtual museum for the recovery of Historical Memory}

\section{Nuria García Gutiérrez ${ }^{\mathrm{a}}$, Oscar Ruiz López}

aÁrea de Exposiciones de la Universidad de Cantabria, nuria.garcia@unican.es, b3D-INTELLIGENCE, oscar.ruiz@3dintelligence.es

\begin{abstract}
Resumen
El patrimonio cultural universitario se caracteriza por su dispersión, variedad tipológica, dificultades de conservación o la falta de recursos económicos para su difusión. Las nuevas tecnologías resultan esenciales para difundir y hacer accesible a todos los públicos este tipo de patrimonio cultural.

La UC no dispone de un museo universitario que conserve, investigue y difunda su patrimonio, sino que dispone de colecciones museográficas universitarias con diferentes secciones bien organizadas. La sección de obra gráfica, con más de tres mil grabados y dibujos tiene una complicada conservación y no puede estar permanentemente expuesta. Las nuevas tecnologías permiten conocer estas piezas mediante el uso de visitas o exposiciones virtuales.
\end{abstract}

La Universidad de Cantabria ha desarrollado diversos proyectos de difusión a través de internet desde el 2008, conjugando investigación, difusión y accesibilidad. Su punto de partida fue la creación del Gabinete de Estampas Virtual que recogió y digitalizó el conjunto de arte gráfico de la entidad. Ya en 2015, tras la denominación de Colección Museográfica se ha desarrollado el proyecto de página web "Patrimonio Cultural Universitario UC", en donde se recogen las distintas tipologías patrimoniales, así como, paseos virtuales $360^{\circ}$ por algunos edificios y zonas del campus.

Desde principios de 2020 y, acelerado por la evolución de la pandemia COVID 19, el Área de Exposiciones del Vicerrectorado de Cultura y Participación de la institución, ha diseñado un museo virtual de uno de los Fondos de su sección de obra gráfica, que de otra forma no podrían ser expuestos de forma permanente. Se trata del legado Paul Quintanilla, depositado por la Fundación Bruno Alonso y que recoge más de 80 obras que el creador cántabro Luis Quintanilla Isasi (1893-1978) realizó desde los años treinta hasta mediados del siglo XX. Su figura como artista plástico y su compromiso político antes y después de la guerra civil española pretenden ser recuperados en el museo virtual "Luis Quintanilla, Arte y Memoria". El 
proyecto conjuga nuevas tecnologías y la rehabilitación de la Memoria Histórica o Democrática a través del arte conjugando la interactuación del espectador con un discurso museográfico que pone en relación piezas que el artista realizó de la Colección UC y otras conservadas en Estados Unidos o en el MNCARS.

Palabras clave: Patrimonio. Universidad. Virtualización. Guerra civil. Exilio

\begin{abstract}
The university's cultural heritage is characterized by its dispersion, variety of typologies, difficulties for its conservation or a shortage of economic resources for his dissemination. The use of new technologies gives an opportunity to make accessible this type of cultural heritage accessible to citizenship.

The UC does not have a university museum to preserve, research, and disseminate its heritage, but instead, it does have university museographic collections with different well-organized sections. The print section, with more than three thousand drawings and engravings, cannot be permanently exposed. The new technologies allow to the knowledge of this pieces through the use of virtual exhibitions.
\end{abstract}

Since 2008, the University of Cantabria has developed various projects through the internet, combining research, dissemination and accessibility. Its starting point was the creation of the Virtual Print Cabinet that collected and digitized the entity's graphic art collection. Already in 2015, after the denomination of Museographic Collection, the web page project "UC University Cultural Heritage" has been developed, where the different types of heritage are collected, as well as $360^{\circ}$ virtual tours of some buildings and areas of the campus.

Since the beginning of 2020, and accelerated due to the evolution of Covid 19, the Exhibitions Area for the Vice-Chancellor's Culture of the university has designed a virtual museum of one of the collections of its graphic work section, which otherwise could not be exhibited permanently. This is the Paul Quintanilla Art Legacy, deposited at the UC by the Bruno Alonso Foundation, which includes more than 80 works that the Cantabrian creator Luis Quintanilla Isasi (1893-1978) produced from the 1930s to the middle of the 20th century. His figure as a plastic artist and his political commitment before and after the Spanish civil war are to be recovered in the virtual museum "Luis Quintanilla, Art and Memory". The project combine the new technologies and the rehabilitation of Historical or Democratic Memory through art, combining the interaction of the spectator with a museographic discourse that relates 
pieces that the artist made from the UC Collection and others conserved in the United States or in the MNCARS.

Keywords: Heritage. University. Virtualisation. Civil War. Exile. 


\section{Introducción}

La situación inusual motivada por la pandemia del COVID-19 ha motivado la reorganización y adaptación de muchos aspectos de la vida cotidiana. Las instituciones públicas o privadas no han permanecido al margen y han tenido de reorganizar su personal, procesos de trabajo o sus programas de difusión.

Los museos y resto de sectores culturales, tras el bloqueo inicial que muchos de ellos tuvieron en los primeros momentos del confinamiento, vieron en sus webs un vehículo de exportación de su trabajo inundando a la ciudadanía de una inusual oferta cultural fuera de sus paredes. Algunos, nos podemos imaginar, fueron improvisando recursos gracias a la voluntad y profesionalidad de sus trabajadores, y otros pudieron utilizar materiales que durante los últimos años habían venido desarrollando. Este es el caso de la Colección Museográfica de la Universidad de Cantabria. Los diversos trabajos de digitalización, investigación y difusión realizados desde el año 2002, permitieron que su oferta expositiva y parte de su patrimonio cultural universitario pudieran durante el confinamiento ofertarse, en acceso libre, a la sociedad mediante el uso de su web y redes sociales. Sus publicaciones fueron incluidas en la iniciativa del Comité Internacional de Museos y Colecciones Universitarias, dependiente del ICOM, "University Museums from Home", de unificar algunas iniciativas similares del ámbito universitario internacional (Cioppi, 2021).

Aunque el discurso museográfico del museo virtual "Luis Quintanilla, arte y memoria" estaba bastante avanzado, la imposibilidad de realizar otras exposiciones en los espacios expositivos supuso un motivo para acelerar el proyecto e iniciar su diseño y desarrollo definitivo. La UC desde el año 2015 había enmarcado en su proyecto web sobre el Patrimonio Cultural Universitario varios recursos virtuales para conocer parte de su campus y sus bienes. Paseos virtuales o el modelado 3D (García, 2017) eran algunos de los recursos que acompañaban al catálogo web que recoge las distintas tipologías patrimoniales de la colección (patrimonio artístico, arquitectónico, científico-técnico, bibliográfico, documental y natural).

Los trabajos de digitalización de los bienes culturales, accesibles vía web, de la UC tienen sus inicios con la creación en el año 2007 del Gabinete de Estampas Virtual. Dicho recurso ha revelado con el paso de los años que es una herramienta de documentación, investigación y difusión consolidada, a pesar de que quizás actualmente, y dados los avances técnicos, su apariencia física ante el usuario esté obsoleta. Se trata de una base de datos en colaboración con la Biblioteca Universitaria de la UC, alojada en el catálogo de dicha unidad, que permite la visualización de la sección de arte gráfico de la colección, así como, los catálogos publicados de dicha sección de la colección. Gracias al recurso, numerosas instituciones nos han solicitado préstamos expositivos, cesión de imágenes para publicaciones, documentales, etc.

La UC no dispone de museos en sus instalaciones y sólo están expuestas ciertas secciones de su colección vinculadas al patrimonio artístico, científico docente y patrimonio natural, en algunos edificios de la institución. El Fondo Paul Quintanilla, 
depositado por la Fundación Bruno Alonso en el año 2005, se conserva físicamente en el Gabinete de Estampas "Pedro Casado Cimiano" y gracias a este proyecto conformará el primer museo de la institución, cumpliendo las actividades de conservación, investigación, comunicación y exposición del museo tradicional (ICOM, 2007) aunque tenga como espacio físico la red.

\section{Características de una colección universitaria}

\subsection{Definición del patrimonio cultural universitario}

El patrimonio cultural universitario es muy variado en cada una de las instituciones y no dispone de un protocolo de protección específico. Solo disponemos de recomendaciones para su conservación y, de entre las definiciones que encontramos la más reseñable es la del Comité Internacional de Museos y Colecciones Universitarias dependiente del ICOM (García, 2016). Las diversas tipologías patrimoniales, materiales e inmateriales, nos ayudan a reconstruir su historia académica, así como la de su comunidad universitaria y la sociedad en la que se enmarca. En nuestro país tenemos universidades públicas con más de ochocientos años, así como, universidades que apenas pasan varias décadas, lo cual implica que hay bienes muebles, arquitectónicos o inmateriales que están protegidos dentro de la legislación en patrimonio cultural vigente, pero también muchos bienes que por su fecha no entran dentro de esta protección.

Por otra parte, la variedad tipológica de materiales y su dispersión en los campus universitarios impiden la creación, en muchas ocasiones, de museos de nivel global e institucional, puesto que serían acumulaciones de cosas sin un discurso expositivo coherente. Es por ello que es habitual que convivan colecciones y museos en diversos centros, facultades o institutos de cada entidad sin ninguna vinculación entre ellos. Esta característica unida a la falta generalizada de presupuesto, hace inviable en muchos casos que las piezas estén inventariadas, catalogadas, conservadas y expuestas en condiciones óptimas. En el caso español, desde hace unos años varias universidades, entre las que destacan la Complutense y Autónoma de Madrid, Granada, Valencia, Cantabria, etc. están intentando crear una normalización, buscando una visibilidad dentro de la Conferencia de Rectores (CRUE) que ayude a sacar a la luz los numerosos trabajos existentes y la necesidad de concienciar, tanto al Ministerio de Cultura como al Ministerio de Universidades, en la necesidad de dotar en los presupuestos de cada universidad partidas que permitan su difusión, investigación y conservación.

Es por ello que la adaptación y uso de recursos vinculados con las nuevas tecnologías, y más tras el inicio de la era COVID que estamos viviendo en la actualidad, se estén generalizando. Ya en el año 2002 el UMAC recomendaba, en el caso de no disponer de medios suficientes para una correcta exhibición, la difusión de estas tipologías 
patrimoniales virtualmente de alguna forma. El desarrollo de los programas informáticos, aplicaciones, bases de datos, así como, la generalización de las redes sociales en la vida cotidiana están facilitando la puesta en marcha de proyectos de difusión de museos y colecciones universitarias con mayor o menor complejidad técnica, dependiendo de los recursos tanto financieros como de recursos humanos que cada entidad dispone.

\subsection{Características de la Colección Museográfica de la UC}

La Colección Museográfica dispone de 5 secciones reconocidas por el Gobierno de Cantabria desde el año 2015: Arte Gráfico, Patrimonio mineral y natural, Colección de Artistas de Cantabria por la Paz, Patrimonio bibliográfico y documental de la Biblioteca Universitaria y el conjunto de murales "Ama la Paz, Odia la Guerra". Además de estas secciones existen colecciones acumuladas en centros y facultades expuestas con mayor o menor fortuna o, simplemente, acumuladas en despachos, seminarios o almacenes.

Dada la juventud de la UC, no llega a los cincuenta años en el desarrollo de su actividad académica, y las características de la docencia impartida, en donde priman las titulaciones eminentemente politécnicas, el patrimonio científico técnico acumulado en las funciones de docencia e investigación tiene un porcentaje alto de representación, más de un $33 \%$, aunque la sistematización en su catalogación no ha comenzó hasta el año 2015 con la puesta en marcha del Proyecto Web de Patrimonio Cultural Universitario UC. Hasta esa fecha muchos de esos bienes ni siquiera estaban inventariados o registrados puesto que sus procedencias eran variadas (cesiones, depósitos, regalos, etc.). Estas características determinan que muy pocos bienes estén expuestos de forma permanente.

Este proyecto de difusión se planteó como una iniciativa que aglutinara las distintas tipologías y que permitiera ir añadiendo nuevos bienes a la vez que se iban registrando e inventariando en unos campus dispersos y alejados unos de otros.

La herramienta planteada era catálogo online pero también optó por la estrategia de realizar visitas virtuales a varios centros en donde se aglutinaba gran parte del patrimonio artístico. Se trata del antecedente directo al proyecto descrito en esta comunicación, es decir, se trata de una evolución y consolidación de los recursos virtuales para difundir, no sólo dentro de la comunidad universitaria, sino también para la sociedad en general un patrimonio que en otras circunstancias no puede ser conocido por el público.

\section{La recuperación de la figura de un artista olvidado.}

Luis Quintanilla Isasi (Santander, 1893-Madrid, 1978) y la Universidad de Cantabria llevan su nombre unido desde que la entidad, en el año 2005, produjo una exposición temporal de dibujos y grabados del creador cántabro, propiedad de la Fundación Bruno Alonso tras la donación por parte del hijo del artista, Paul Quintanilla, residente 
en Estados Unidos a dicha Fundación. Hasta ese momento el actual Museo de Arte Moderno y Contemporáneo de Santander (MAS), anteriormente Museo de Bellas Artes), disponía de la mayor acumulación de obra del pintor en España. Durante esa exhibición de 2005, se realizaron diversas conferencias y debates sobre la recuperación de la figura del artista y su importancia en la historia del arte y su compromiso político puesto que el paso de los años y la dictadura franquista habían borrado del panorama artístico español su memoria.

Las piezas expuestas, posteriormente, fueron depositadas en la futura Colección Museográfica de la UC y desde el año 2006 forman parte dentro de su sección de obra gráfica. Como ocurre con otros fondos de esta sección, su inventario, catalogación, digitalización y difusión se realizó con la pretensión de que formasen parte del Gabinete de Estampas Virtual de la UC.

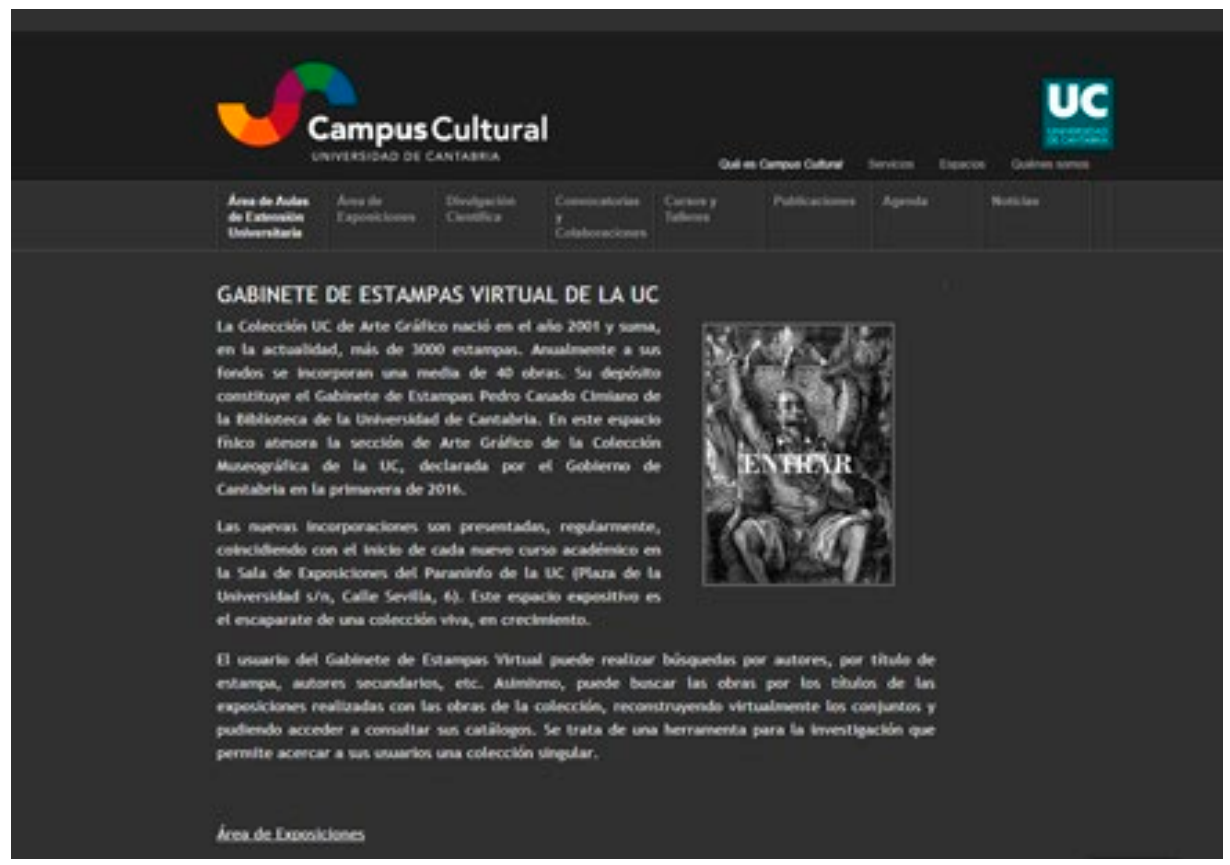

Fuente: Universidad de Cantabria

Fig 1. Web del Gabinete de estampas Virtual de la Universidad de Cantabria

\subsection{Apuntes biográficos sobre Luis Quintanilla}

Luis Quintanilla era casi un desconocido para la población de Cantabria y del resto de España. Su trayectoria artística le había llevado en 1912 a trasladarse a Francia donde mantuvo contactos con el círculo de Juan Gris, Chagall o Modigliani. En 1914 reside en Alemania donde contactó con el expresionismo y tras un nuevo paso por París, regresó a España en 1915. Su espíritu bohemio chocaba con la sociedad santanderina, 
por lo que en 1916 decidió trasladarse a Madrid y así ampliar sus contactos con creadores como Gerardo de Alvear, Vitorio Macho o Antonio Machado y con intelectuales y políticos como Luis Araquistáin o Juan Negrín. Hacia 1920 regresó al contexto parisino en donde inició su amistad con Ernest Hemingway. En 1924 se le concedió una beca de la Junta de Ampliación de Estudios que le llevó a Italia a conocer, de primera mano, la técnica del fresco que le interesaba desde que hubiera conocido los frescos de la colegiata de San Isidoro de León en 1916. Durante su estancia en Italia conoció el ascenso del fascismo con "los Camisas Negras", hecho que le incitó a desarrollar más su espíritu crítico y su conciencia política. Tras su regreso a España en 1925, sus contactos con escritores como Unamuno o Valle Inclán fueron frecuentes y su fama como fresquista se fue incrementando, lo que motivó que en 1927 el duque de Alba le encargase una serie de frescos para el Palacio de Liria o en 1929 realizará unos frescos para el Consulado de Hendaya. A partir de 1930 comenzó a conocer las técnicas de grabado de la mano del maestro grabador de Calcografía Nacional Adolfo Rupérez. Para esa fecha, todo parece indicar que se ha afiliado al PSOE, lo que motivó su participación activa en el advenimiento de la Segunda República y determinó que le encarguen los frescos de la Casa del Pueblo de Madrid, así como, el mural titulado "Mujeres" para el Museo de Arte Moderno, conservado en la actualidad en el Museo Nacional Centro de Arte Reina Sofía (MNCARS) y que, hasta el año 2007, era el único mural conservado en España. Durante las revueltas de 1934, Quintanilla fue apresado por desarrollar en su estudio una reunión del Comité Revolucionario, lo que motivó su ingreso en la Cárcel Modelo. Posteriormente, cuando fue liberado, en junio de 1935, su compromiso con la República aumentó, coincidiendo con el encargo del "Monumento a Pablo Iglesias" en el que estaba trabajando cuando se inició la guerra civil. El 19 de julio de 1936 recibió el encargo de dirigir el asalto al Cuartel de la Montaña y, posteriormente, participó en el asedio al Alcázar de Toledo. Por otra parte, sus contactos le llevaron a participar en la Alianza de Escritores Antifascistas que primero tiene su sede en Madrid y después en Valencia. También formó parte de la Junta de Incautación y Protección del Tesoro Artístico, aunque todo parece indicar que no tuvo una actividad muy continuada. En 1937, tras formar parte de la denominada "Red Quintanilla" de espionaje, bajo el mando del embajador español en Francia, Quintanilla recorrió varios frentes tomando notas y apuntes de los bombardeos y destrucciones que vio en localidades como Santa María de la Cabeza, Madrid, Pozoblanco, Córdoba, etc. Los dibujos finales los realizó durante una posterior estancia en la casa del pintor Joaquín Sunyer y fueron inicialmente expuestos en Barcelona, formando también parte de su exposición en el MOMA en 1938, denominada "Ama la Paz y Odia la Guerra” y que hizo itinerante por Estados Unidos la Fundación Rockefeller.

La temática antifascista y la denuncia del conflicto español caracterizaron estos años en su panorama creativa. El éxito obtenido motivó el encargo del gobierno republicano de realizar una obra que representara a España en el pabellón de la nueva exposición internacional de Nueva York en 1939. Quintanilla se trasladó a la ciudad 
americana para realizar su obra en la que utilizó la técnica del fresco, técnica que encajaba en su idea de utilizar el arte como vehículo de denuncia social y del fascismo. Creó cinco murales exentos formando un políptico que tomaron el título general de la exposición realizada en el MOMA, “Ama la Paz y Odia la Guerra”, en donde cada mural representa una temática vinculada a "los desastres de la guerra": Soldados, Huida, Hambre, Destrucción y Dolor. El conjunto nunca fue expuesto en la exposición para la que se crearon, ya que la guerra civil terminó y el gobierno franquista borró cualquier pieza que tuviera algo que ver con la República de su pabellón. Es el inicio de su exilio personal y le motivó a que el conjunto de murales, conocido como "Los otros Guernicas", fuese expuesto junto a sus bocetos en la Associated American Artist. (LÓPEZ, 2005).

De esta forma comienza la leyenda/historia de estas obras, que terminó con su traslado en 2007 a España y que desde entonces son expuestas en la UC. Quintanilla, tras esa exposición y ante las reclamaciones de la devolución del dinero, por parte del gobierno republicano en el exilio, cobrado al inicio del encargo, Quintanilla optó por esconder las obras y manifestar que se habían destruido, permaneciendo casi ocultas en los pasillos del local donde se expusieron y que, con el paso de los años, se convirtió en un lugar de cine de culto del colectivo bohemio del Village neoyorquino, pasando posteriormente a un cine porno-gay, hasta su desmantelamiento a finales de los años 90. Para esas fechas, el profesor Jerald Green había localizado las obras y junto a la investigadora Esther López Sobrado habían intentado involucrar en un posible rescate al gobierno español (LUJÁN, 2). La operación no se pudo materializar puesto que el propietario del cine pidió una cantidad desorbitada para su posible venta. Hubo que esperar a que en octubre de 2007, la Universidad de Cantabria consiguiera el mecenazgo del Banco Santander para su rescate, traslado a España y restauración, hasta entonces, las obras permanecieron olvidadas, como la figura de Luis Quintanilla.

Durante sus primeros años de exilio, su denuncia en contra del fascismo centraba gran parte de sus obras como la serie de acuarelas "Europa Totalitaria" o los frescos que realizó durante su estancia como profesor en la Universidad de Kansas City, en la que fue la primera escuela de pintura al fresco en tierras estadounidenses entre $1940 \mathrm{y}$ 1941, posiblemente su último trabajo como fresquista, una obra madura en la que plasma un Don Quijote y sus batallas durante el siglo XX, cuyo título es "Las andanzas de D. Quijote y Sancho Panza en el siglo XX”.

La imagen de una Europa en manos del totalitarismo ayudó a que el artista no se planteara volver a una España que, poco a poco, estaba inmersa en la dictadurafranquista, en donde no había lugar para los intelectuales afines a la República. Conjugó obras como retratista, incluso de alguna estrella de Hollywood, con su faceta como ilustrador de obras de escritores consagrados como Edgard Alan Poe o Jonathan Swift, con otros textos menos conocidos a lo largo de su estancia en América y sus años en Francia. Quintanilla no regresaría a Santander, nunca más. Volvería a España en 1976 a Madrid y por unas semanas no pudo acudir a la 
exposición monográfica retrospectiva de su obra que se preparaba en el Museo de Bellas Artes de Santander en 1978 porque falleció.

La labor que ha desarrollado la Universidad de Cantabria desde el año 2005 de difusión y puesta en valor de la figura de Quintanilla ha buscado utilizar su compromiso antibelicista y de denuncia social como eje vertebrador de las diversas actividades desarrolladas dentro del ámbito universitario, así como, las dedicadas al público en general. Los fondos conservados en nuestra universidad son un total de 80 grabados y dibujos, así como el conjunto de cinco frescos realizados sobre la Guerra Civil. A lo largo de estos años, 7 exposiciones temporales dentro y fuera de Cantabria, así como la exposición permanente de conjunto de murales se han alternado con proyecciones de documentales, conferencias, diversos catálogos y monografías publicados, mesas redondas y otras exhibiciones durante las conmemoraciones del 75 y 80 aniversario del final de la guerra civil. Los frescos "Ama la Paz y Odia la Guerra", obtuvieron en el año 2014 el reconocimiento público y artístico con su declaración como Bien de Interés Cultural, hecho que supuso el reconocimiento de la obra de un artista olvidado y su memoria por parte de su ciudad y su región natal, un olvido motivado por la contienda civil y dictadura.

\section{Nuevos recursos, nuevas experiencias.}

Desde su ingreso en la Colección Museográfica del conjunto de piezas realizadas por Quintanilla, la institución desarrolló su inventario, catalogación y digitalización abierta al público en el mencionado Gabinete de Estampas Virtual, en el caso de los dibujos y estampas.

De esta forma desde el año 2007, las obras eran accesibles para el público en general e investigadores a modo de catálogo, incluyendo las publicaciones editadas por la institución. Su navegación o búsquedas no permitían que el posible visitante tuviera una gran interactuación con los contenidos.

Hemos tenido que esperar a fechas más cercanas, al año 2018 para desarrollar, gracias a las nuevas tecnologías, navegaciones web por las distintas colecciones de algunos de nuestros edificios o del Campus en paseos virtuales. Conscientes de las limitaciones que tiene la institución por falta de espacios expositivos y recursos económicos, se ha optado por desarrollar estos recursos con el fin de otorgar accesibilidad a ciertos fondos que, de otra forma, la sociedad en general no estaría dispuesta a visitar. Es decir, la búsqueda de la accesibilidad y de la empatía de los potenciales públicos es una de las funciones que se han buscado.

La obra de Quintanilla fue una de las seleccionadas, exactamente, el conjunto de murales expuestos en el Paraninfo de la UC. A través de una visita al edificio, que permite conocer sus diferentes espacios, el visitante puede interactuar con los contenidos leyendo sus descripciones, datos técnicos, viendo sus detalles o incluso 
ver desde distintas perspectivas de la instalación escultórica de Agustín Ibarrola "Nubes de papel" mediante un modelado 3D.

En una época en que los conceptos de la denominada Nueva Museología ya se habían quedado obsoletos, en donde el turismo cultural buscaba la planificación de sus visitas, o reflexionaba sobre ellas a posteriori, mediante las navegaciones en las webs de las instituciones visitadas, este tipo de recursos entendemos que aumenta la empatía del espectador hacia los contenidos visitados, ayudan o completan la planificación de una visita, otorgando una experiencia más placentera que perdurará en la memoria del espectador más tiempo, tanto en los más pequeños como en los visitantes de edad adulta. Los museos y centros culturales desde hace años buscan la "interafectividad" a través de sus webs y redes sociales con los potenciales públicos: "interactividad, interacción y accesibilidad" (Moreno, 2017).

Paradójicamente, todo el trabajo realizado desde el año 2007, permitió que en el año 2019 comenzáramos a trabajar en la posibilidad de crear exposiciones y museos virtuales de algunas colecciones, gracias a la experiencia obtenida con los paseos virtuales mencionados anteriormente recogidos dentro del proyecto de Patrimonio Cultural Universitario o la exposición temporal realizada en colaboración con el Real Jardín Botánico CSIC, Maria Sybilla Merian y Alida Withoos: Mujeres, Arte y Ciencia en la Edad Moderna.

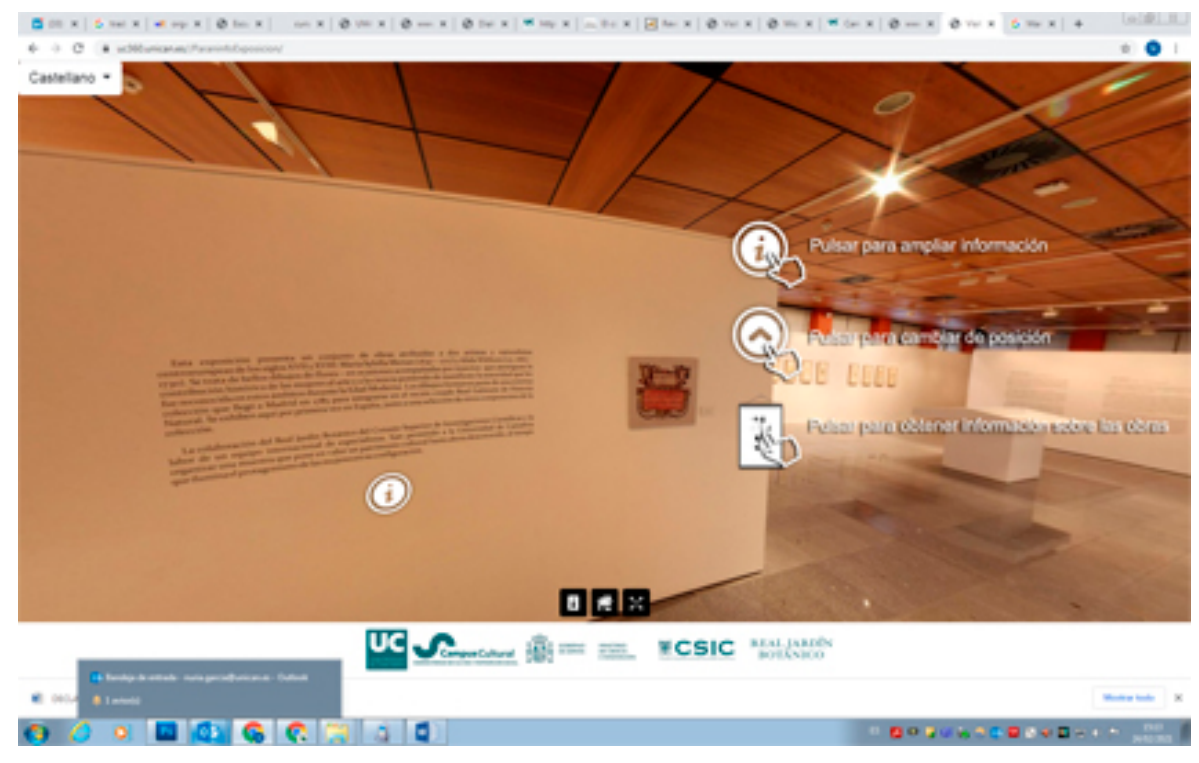

Fuente: Universidad de Cantabria

Fig. 2 Visita virtual a la exposición Maria Sybilla Merian y Alida Withoos: Mujeres, Arte y Ciencia en la Edad Moderna. 


\subsection{Museo virtual: Luis Quintanilla, arte y memoria}

\subsubsection{Objetivos del proyecto}

Un museo sobre Luis Quintanilla era una reivindicación de una parte de ciertos sectores de la cultura de Cantabria, pero presupuestariamente ha sido imposible de desarrollar por parte de la UC. Su posible versión virtual disponía ya de un incipiente discurso y diseño museográfico cuando en marzo de 2020 la COVID-19 llegó a nosotros. El contexto que se vivía y el desarrollo de múltiples actividades culturales a través de recursos web fue el punto de partida para poder materializar la propuesta encabezada por el Área de Exposiciones del actual Vicerrectorado de Cultura, Proyección Social y Relaciones Institucionales de la Universidad de Cantabria.

Los objetivos básicos del proyecto era:

- Recuperar la la figura de un artista olvidado en nuestro país y cuya obra ayuda a la recuperación de la memoria histórica y democrática.

- Continuar con la difusión del patrimonio cultural universitario de la entidad, utilizando recursos digitales.

- Agrupar obras dispersas del artista en un solo espacio, de manera atractiva y con un alto grado de accesibilidad.

\subsubsection{Metodología}

Para el desarrollo del proyecto se ha contado con la empresa 3D-Intelligence con quien se habían desarrollado los anteriores recursos virtuales. Se ha planteado como una primera fase de un proyecto más global que genere la visibilidad de un fondo artístico de una forma más atractiva, didáctica e interactiva, independientemente del tipo de público. El proyecto se presentará a partir del mes de mayo de 2021 con versiones en castellano e inglés, además de una lectura adaptada para usuarios con discapacidad visual y está financiado por el Banco Santander.

La visita se ha planteado en el original espacio del Paraninfo de la UC, tomando como referencia su sala de exposiciones, espacio que se ha multiplicado gracias a la tecnología, en varios espacios expositivos, caracterizados por sus paramentos en color negro para la ocasión, respetando el sistema perimetral de muros originales superpuestos a los muros del espacio arquitectónico. De esta forma, el espectador realizará su visita en un espacio real pero adaptado para la propuesta virtual. Está articulada en siete salas en donde se combinan las obras custodiadas en la UC, con otras obras del artista conservadas en el MNCARS o en la Universidad de Kansas City, así como pequeños videos explicativos. El recorrido expositivo permite unir obras que nunca se han expuesto juntas y que permanecen conservadas en distintas instituciones: 
- Sala 1: Contexto histórico de la vida de Luis Quintanilla y estampas de los años treinta de tipo social.

- Sala 2: Dibujos sobre su encarcelación en 1934.

- Sala 3: Dibujos de la guerra civil: Dibujos sobre los diferentes frentes que visita durante la guerra y la serie Francos's Black Spain.

- Sala 4: Ama la Paz y Odia la Guerra: posibles ubicaciones para la Exposición Internacional de Nueva York de 1939.

- Sala 5: Localización en la actualidad del conjunto de murales Ama la Paz y Odia la Guerra en el Paraninfo de la Universidad de Cantabria.

- Sala 6: Exilio: Murales de la Universidad de Kansas City y serie Europa Totalitaria.

- Sala 7: Quintanilla como ilustrador y dibujante.

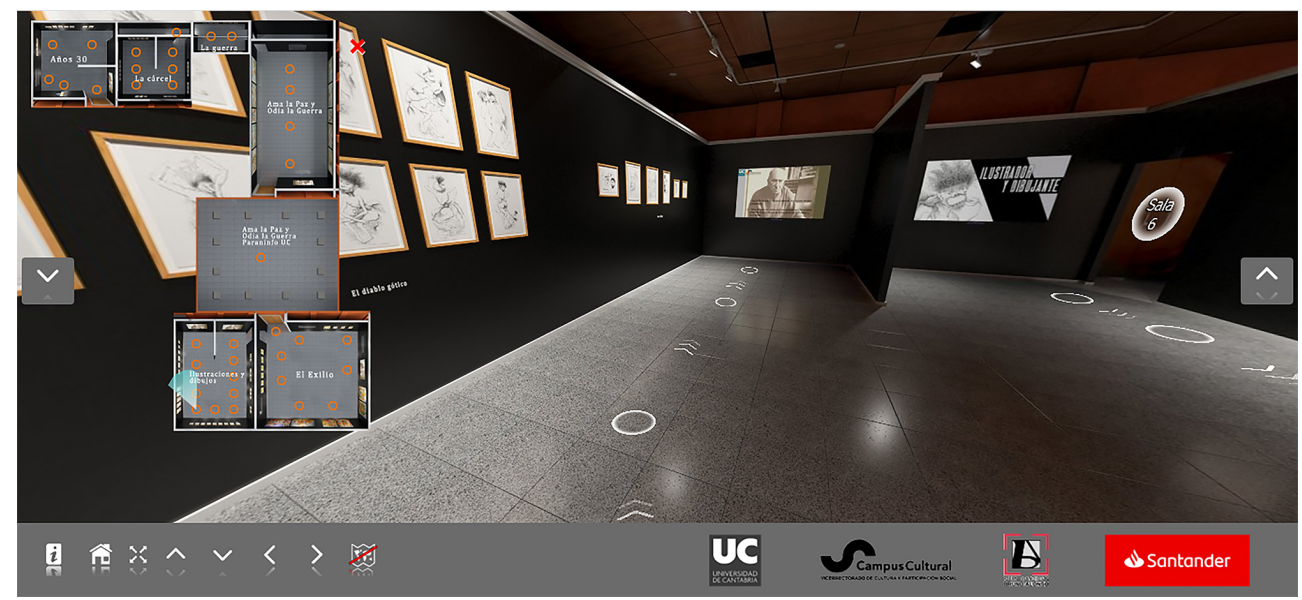

Fuente: Universidad de Cantabria

Fig. 3 Vista "Museo Luis Quintanilla"

$\mathrm{Su}$ discurso temporalmente se encuadra desde los años treinta hasta los años sesenta: República, Guerra Civil y Exilio. La narración tiene un eje central que es el compromiso del artista a la hora de utilizar las artes plásticas como vehículo de denuncia política y social del contexto histórico que le toca vivir. Grabados, dibujos, acuarelas o frescos se distribuyen sobre los paramentos virtuales separados y agrupados con textos, simulando aplicaciones de vinilo calado a pared, y alternándose con fragmentos de video de diversos personajes históricos, investigadores, políticos e intelectuales que conocieron a Quintanilla o han estudiado su figura. Parte de los fragmentos, pertenecen al documental realizado en 2009 por el director cántabro Iñaki Pinedo y producido por la UC, el Banco Santander y el Gobierno de Cantabria. 
El visitante/usuario puede acercarse a los contenidos y pinchar en cada una de las obras expuestas para así poder ver cada imagen en alta resolución y su descripción con detalles técnicos. La navegación se facilita con un plano de la muestra que permite pasar de una sala a otra sin seguir su discurso.

La web de Campus Cultural UC acogerá la muestra con una página de inicio que presentará el proyecto y agrupará en un mismo espacio, materiales didácticos, bibliografía, hemeroteca y otro tipo de enlaces web de interés que completaran el proyecto.

\subsection{Descripción técnica del proyecto de museo virtual.}

Museo Virtual: Luis Quintanilla, arte y memoria es un ambicioso proyecto en el que se presenta un formato museístico innovador, a través de entornos completamente virtuales y contenido real del artista.

Se ha desarrollado un entorno virtual basado en el espacio original del Paraninfo de la UC, y tomando como referencia su sala de exposiciones. El espacio ha sido escalado para poder albergar la amplia colección. Han sido analizas todas las obras, sus dimensiones, y se han repartido en 7 salsa diferentes. Cada sala ha sido diseñada en función de las características de las obras que alberga. Dando lugar a salas con diversa morfología.

Es escenario virtual ha sido diseñado y representado respetando la actual morfología de la sala de exposiciones real del Paraninfo de la UC, siendo fiel también en el nivel de detalle y realismo de las texturas utilizadas. La iluminación ha sido recreada siempre teniendo en cuenta el sistema real de iluminación de la sala de exposiciones real del Paraninfo, aplicando archivos en formato fotométrico que simulan la iluminación real.

El modelado ha sido generado íntegramente en software de diseño Blender, así como el texturizado y la posterior iluminación. Para el texturizado se han utilizado materiales con textura fotorrealista optimizadas, así mismo se han utilizado mapas de color realistas complementados con los correspondientes mapas de normales, desplazamiento y rugosidad con el fin de obtener un algo grado de detalle y realismo vial, siempre respetando el tipo de material utilizado en la sala real.

Los mapas UVW de cada elemento de la sala han sido ajustadso individualmente, con el fin de obtener un modelo sostenible cada objeto y los objetos que componen a estos (geometrías hijo y texturas), estando identificadas independientemente. Una vez ha sido completado el modelado de todo el entorno con todas las salas que lo completan se han modelado independientemente los elemento que soporta cada obra, a modo de "marcos", sobre estos y utilizando la metodología de aplicación de texturas se ha colocado cada obra correctamente escalada y ajustada a sus dimensiones reales en cada "marco".

Las obras se han agrupado por temáticas, dicha temática siempre asesorado por la dirección del proyecto es completada con textos descriptivos sobre los muros de la sala. Para la representación de los mismos se ha trabajado con los diferentes canales de las texturas para superponer dichos textos. 
Una vez finalizada la recreación virtual de todo el entorno y sus correspondientes obras se ha procedido a diseñar el recorrido virtual a realizar por toda la exposición colocando las correspondientes cámaras en las escena que corresponderán con los puntos de visualización de la exposición.

La generación de contenido para el montaje de la visita virtual se fundamenta en la navegación entre escenas panorámicas $360^{\circ}$. Dichas panorámicas se han generado renderizado salidas gráficas con resoluciones mínimas de 10.000 x 5.000 pixel.

Se ha generado contenido visual asociado cada una de las obras de la exposición, esta información es ofrecida a lo largo de la visita virtual interactuando con las obras. Se ofrece información añadida de la obra y se facilita poder realizar zoom sobre la imagen en alta resolución. También han sido asociados a la visita virtual una serie de videos documentales sobre Luis Quintanilla y su obra, estos se han posicionado sobre elementos modelados virtualmente que simulan pantallas.

Tras la producción y procesado de todas las escenas panorámicas $360^{\circ}$ estos son tratados en software específico para ser fraccionados en imágenes de menor tamaño, creando un mosaico de imágenes. Cada componente de este mosaico tiene asignado un pitch y un YAW que define su posicionamiento. Con este proceso se optimiza la navegación por visita virtual, ya que el navegador solo carga las imágenes que se muestran en pantalla, en lugar de toda una imagen $360^{\circ}$ de gran tamaño.

Los mosaicos son llamados desde un documento JAVASCRIPT, cada mosaico constituye una "escena", dentro de la cual las imágenes se rotan para conseguir el efecto de libertad de movimiento $360^{\circ}$ alrededor de cada posicionamiento. Se puede limitar el PITCH y YAW de giro máximo, para enfocar el tour en ciertos elementos.

Para realizar los cambios entre escenas se carga un nuevo mosaico de imágenes, este cambio de escena se solicita a través de una serie de marcadores posicionados en la escena con los que se puede interactuar. Mediante un enlace $(<\mathrm{a}>$ ) de HTML, se solicitan los cambios entre escenas. Los contenidos asociados a las obras son elementos HTML "modal", para mostrar estos contenidos asociados a las obras se han generado marcadores posicionados sobre cada una de ellas, los marcadores tienen definido su correspondiente PITCH y YAW de posicionamiento de este modo quedan asociados al entorno mosaico generado y se desplazan acompañando el movimiento que el usuario este realizando.

Los video documentales asociados a la visita virtual, posicionados sobre la recreación de pantallas, son adjuntados usando elementos HTML "iframe" para reproducirlos desde webs dedicadas a hospedar videos (Youtube, Vimeo, DailyMotion, etc.), de esta manera se optimiza la visita.

\section{Futuro próximo y conclusiones}

Como hemos indicado, este proyecto forma parte de una intervención más global de difusión de la obra de Luis Quintanilla que viene desarrollándose desde hace varios 
años. Además de esta iniciativa, se pretende realizar, en un futuro próximo, un proyecto para descarga en móviles de guía de visita y realidad aumentada sobre el conjunto de murales del Paraninfo de la UC, dadas las circunstancias actuales motivadas por el COVID que no permiten el uso de folletos en papel y las visitas formales de grupos numerosos. Esta iniciativa permitiría completar los actuales códigos QR con las descripciones en archivo pdf descargable por parte de los potenciales visitantes.

La visibilidad otorgada por todos estos recursos a la colección de obras de Quintanilla permite que estas piezas dispersas y cuyo soporte papel es altamente frágil, sean conservados en las mejores condiciones ambientales, puesto que su digitalización permite acceder a ellas en alta calidad, además de permitir un seguimiento comparado del envejecimiento de las piezas gracias a esas reproducciones.

Ha permitido la colaboración entre diversas entidades públicas y privadas permitiendo crear una exhibición con un discurso más completo y amplio, no sólo en cuanto a número de obras, sino también en cuanto a las temáticas abarcadas, incidiendo en el compromiso político del artista y su plasmación en sus creaciones pictóricas.

Aunque somos conscientes de las distintas tipologías de los potenciales usuarios y sus diversas preferencias de navegación, entendemos que una navegación intuitiva en donde el espectador escoge los apartados en donde profundizar sus conocimientos puede ayudar a que el tiempo dedicado a la visita sea lo más amplio posible, se repita a lo largo del tiempo y pueda satisfacer a todos los públicos gracias a la interactuación con los contenidos.

Un museo permanente de estas características requiere una financiación grande y permanente en el tiempo. Somos conscientes de que con el paso de los años y los avances tecnológicos requerirán una necesaria renovación de la presentación de los contenidos, pero entendemos que puede ser mucho más económico para la institución el mantener este tipo de herramientas.

Finalmente, la experiencia que tenemos a la hora de comprobar la puesta de contenidos en abiertos de nuestra colección en recursos web, nos indica que la red es un excelente escaparate para que investigadores, gestores culturales, editores, autores, coleccionistas, productoras audiovisuales, instituciones o diversos colectivos conozcan nuestras colecciones puesto que gracias a esta difusión a lo largo de estos años han contactado, en numerosas ocasiones, con nuestra entidad para el préstamo expositivo, solicitud de información o de reproducciones para distintos usos. Esto nos hace pensar que mantener iniciativas de estas características ayudan a que la colección crezca, se conozca, se conserve y se investigue, no solamente desde la Universidad de Cantabria, sino también desde otras partes del mundo, es decir, que la complementación de estas actividades puede ayudar a que este tipo de museos virtuales respeten la definición de museo tradicional a pesar de que el espacio físico esté en la red. 


\section{Referencias}

CIOPPI, E. et al. (2021). "University Museums from Home: observations on responses to the impact of Covid-19", en University Museums and Collections Journal. A journal about museology and higher education, Vol. 12, $\mathrm{n}^{\mathrm{o}}$ 2, pp. 138-158 Disponible en $<$ http://umac.icom.museum/wp-content/uploads/2021/01/UMACj-12_2-web.pdf [Consulta: 22 de febrero de 2021].

DIAZ REDONDO, J. (2012) "Patrimonio universitario, patrimonio virtual. University heritage, virtual heritage", en Educación y Futuro: revista de investigación aplicada y experiencias educativas, 27, pp. 121-137. Disponible en $<$ https://dialnet.unirioja.es/descarga/articulo/4060941.pdf $>$. [Consulta: 22 de febrero de 2021].

GARCÍA GUTIÉRREZ, N. (2016): "Nuevas tecnologías y difusión del Patrimonio Universitario de la Universidad de Cantabria", en Centeno del Canto, P. en Actas de las 9as Jornadas de Museología del Museo Sierra Pambley: La comunicación y la gestión de la imagen en los museos. León, pp. 219-235 Disponible en http://cursomuseo.sierrapambley.org/ [Consulta: 23 de febrero de 2021]

GARCÍA GUTIÉRREZ, N. "Colecciones artísticas en universidades no históricas". Nuevos retos de difusión. En Congreso Internacional Museos Universitarios. Tradición y futuro, Madrid: Universidad Complutense de Madrid. 187-193.

GARCÍA GUTIÉRREZ, N. y LEAL PÉREZ, I. (2021): “Patrimonio Cultural Universitario: Difusión y accesibilidad virtual" en Museos y Universidades. Espacios compartidos para la educación, la inclusión y el conocimiento, Editorial TREA, pp. 53-70.

GOMEZ MARTÍNEZ, J. (2007). Los frescos de Luis Quintanilla sobre la Guerra. Santander: Universidad de Cantabria.

LÓPEZ SOBRADO, E. (2005). Luis Quintanilla (1893-1978): estampas y dibujos en el legado de Paul Quintanilla [cat. exp.]. Santander: Universidad de Cantabria, Santander.

LÓPEZ SOBRADO, E. (2009). Luis Quintanilla, testigo de guerra [cat. exp.]. Santander: Universidad de Cantabria.

LUJÁN, J. (2007). "Los otros "Guernicas". El País Semanal, $n^{o}$. 1595, Disponible en $<$ https://elpais.com/diario/2007/03/18/eps/1174202160_850215.html>, [Consulta: $22 \mathrm{de}$ febrero de 2021].

MARTÍNEZ RODRIGO, E., SEGURA GARCÍA, R. y SÁNCHEZ MARTÍN, L. (2011). “El complejo mundo de la interactividad: emociones y redes sociales", en Revista Mediterránea de comunicación, 2, pp. 171-190. Disponible en $<$ https://rua.ua.es/dspace/bitstream/10045/18217/1/ReMedCom_02_10.pdf $>$ [Consulta: 22 de febrero de 2021].

MORENO SÁNCHEZ, I. (2004)."Nuevas tecnologías, nuevas formas de difusión del conocimiento" en Museo: Revista de la Asociación Profesional de Museólogos de España, $\mathrm{n}^{\circ} 8, \quad$ Alicante, pp. 233-243. Disponible en 
$<$ https://dialnet.unirioja.es/servlet/articulo? $\operatorname{codigo}=2772520>$ [Consulta: 22 de febrero de 2021].

MORENO SÁNCHEZ, I. (2019). Museística y nuevas redes digitales: en busca de la interafectividad con todas las personas. Madrid: Ed. Fundación Alternativas, pp-99-108. Disponible $<$ https://www.fundacionalternativas.org/public/storage/publicaciones_archivos/36e8ddaea95 99809a584485d2c4bbbe8.pdf>_[Consulta: 22 de febrero de 2021].

UNIVERSIDAD DE CANTABRIA. Exposición virtual: Maria Sybilla Merian y Alida Withoos: Mujeres, Arte y Ciencia en la Edad Moderna. $<$ https://web.unican.es/campuscultural/exposiciones/mujer-arte-y-ciencia-en-laedad-moderna $>$ [Consulta: 22 de febrero de 2021].

UNIVERSIDAD DE CANTABRIA. Gabinete de Estampas Virtual UC< https://web.unican.es/campuscultural/exposiciones/gabinete-de-estampas> [Consulta: 22 de febrero de 2021].

UNIVERSIDAD DE CANTABRIA. Web Patrimonio Cultural Universitario UC, $<$ https://web.unican.es/utiles/patrimonio/>, [Consulta: 22 de febrero de 2021].

UNIVERSIDAD MISSOURI KANSAS-CITY. History of the Haag Hall Don Quixote Mural. Disponible en <https://www.umkc.edu/news/posts/2018/november/history-ofhaag-hall-don-quixote-mural-luis-quintanilla.html>, [Consulta: 22 de febrero de 2021].

UNIVERSITY MUSEUMS \& COLLECTIONS. (2007): Importance, Responsibility, Maintenance, Disposal \& Closure. UMAC guidelines. Disponible en $<$ http://publicus.culture.hu-berlin.de/umac/pdf/statement.pdf $>$, [Consulta: 22 de febrero de 2021]. 